\title{
Tobacco smoking and depression: time to move on to a new research paradigm in medicine?
}

\author{
Peter de Jonge* and Elisabeth Henriette Bos
}

\begin{abstract}
A recent paper published in BMC Cardiovascular Disorders reported on a study into whether tobacco smoking may serve as a risk factor for depression in patients with heart disease. In the current paper, we discuss several limitations of that study, of which many apply not just to the study itself but to the nomothetic research design that was used. Particularly when bidirectionality between variables is expected, fluctuation in variables over time takes place, and/or inter-individual differences are considerable, a nomothetic research approach does not seem appropriate, and may lead to false conclusions. As an alternative, we describe an idiographic approach in which individuals are followed up over time using many repeated measurements, and from which individual models are estimated. Such intensive time-series studies are not common in medicine, but are well described in the fields of econometrics and meteorology. Combining idiographic research designs with more traditional nomothetic designs may lead to research findings that are not only useful for society but also valid in individuals. See related research article here http://www.biomedcentral.com/1471-2261/13/35.
\end{abstract}

Keywords: Tobacco smoking, Depression, Heart disease, Cohort study, Nomothetic, Idiographic

\section{Background}

A vast body of literature has reported on the bidirectional association between tobacco smoking and depression. Individuals with depression have a higher risk of smoking, and a decreased chance of being able to quit smoking [1,2]. Smokers in turn have a higher risk of being depressed and a decreased chance of recovery from depression [3]. Both tobacco smoking and depression are associated with serious health consequences, including incident heart disease. Depression and smoking are both considered risk factors for ischemic heart disease $[4,5]$. In their study published in BMC Cardiovascular Disorders, Stafford et al. [6] followed up 193 patients with heart disease to investigate the prospective association between smoking and depression and healthrelated quality of life. The authors concluded that their findings support a role for smoking as an independent predictor of depression in these patients. However, several limitations of the study challenge this conclusion. Many of these limitations are not confined to the

\footnotetext{
* Correspondence: peter.de.jonge@umcg.nl Interdisciplinary Center Psychopathology and Emotion regulation, University Medical Center Groningen, University of Groningen, PO Box 30.001, 9700 RB, Groningen, the Netherlands
}

Stafford study, but are inherent to the nomothetic research paradigm that dominates medicine.

\section{Limitations of the study}

The Stafford et al. study used an observational cohort design to assess patients after hospital admission for a cardiac event. However, we have identified a number of limitations as follows.

1. The extent to which this sample is representative of patients with chronic heart disease or subclinical forms of (unidentified) heart disease is not clear. Moreover, only 193 (37\%) of 528 eligible patients were included, further reducing the representativeness.

2. The study power was severely limited by the low prevalence of smokers and of subsequent depression. Conclusions were based on 12 smokers with depression versus 23 non-smokers with depression, numbers that do not warrant multivariate models (the authors used 14 predictor variables).

3. There is the problem of reverse causation. It is likely that the baseline measurement of tobacco smoking would have been affected by a preceding state of depression, and consequently, the observed effects

\section{Biomed Central}

(C) 2013 de Jonge and Bos; licensee BioMed Central Ltd. This is an Open Access article distributed under the terms of the Creative Commons Attribution License (http://creativecommons.org/licenses/by/2.0), which permits unrestricted use, distribution, and reproduction in any medium, provided the original work is properly cited. 
may not be fully attributable to smoking. Stafford et al. did try to reduce this effect by statistically controlling for past depression status; however, past depression status (yes/no) is a suboptimal assessment of the confounder. This limitation was further compounded by the fact that smoking was considered only 'predictive' of depression at the first assessment, when smoking and depression were measured simultaneously.

4. Suboptimal confounding control also takes place when not all potential confounders, or the wrong confounders, are entered into the multivariate prediction model $[7,8]$. For example, using only left ventricular ejection fraction to control for the confounding effects of disease severity is unlikely to be sufficient, as the authors also pointed out in their discussion. Likewise, it is unlikely that the models were adequately controlled for confounding by other potential common causes of smoking and depression, such as low self-esteem, emotionregulation problems, low socioeconomic status, or shared genetic factors.

5. Fluctuations in smoking and depression were not taken into account. Many individuals in the study stopped smoking in the months following hospital admission, but they were counted as smokers throughout the study period.

6. Results obtained at the group level were implicitly generalized to the individual level. From the observation that patients who smoke were more frequently depressed compared to non-smokers, the authors concluded that if an individual stops smoking his or her future depression levels will be lower. This jump from the population to the individual level is often made in epidemiological research, but is only justified if the conditions for ergodicity are met, which include homogeneity (that is, for each subject in the population the same statistical model holds) and stationarity (that is, a process has constant statistical characteristics over time) $[9,10]$. If these conditions are not met, making this jump from the population to the individual level can lead to false conclusions. Sometimes associations found at the population level are non-existent or even reversed at the individual level [10-12].

\section{Limitations of the nomothetic approach}

Many studies (including our own!) in the medical field have similar limitations to those cited above. It is not our intention to criticize the Stafford et al. study specifically, but rather to use it as an illustration of the nomothetic research paradigm, of which the applicability is sometimes overstretched. Some fundamental problems inherent to the nomothetic approach compromise the possibility to draw valid conclusions about individuals $[10,13,14]$.

1. Between-subjects heterogeneity is not well accounted for in nomothetic studies, as data are aggregated over groups of individuals. In fact, the nomothetic approach deals with variability between individuals as if it were error, which is probably one of the reasons why small effect sizes and inconsistent study results are so often reported.

2. Many of the phenomena studied in the medical field show large intra-individual variability. Such fluctuations are not adequately captured in nomothetic studies, because these have only a limited number of assessment waves, separated by large intervals.

3. Third, many medical phenomena are characterized by multiple interactions between several factors, mutually reinforcing effects, and feedback loops. Standard nomothetic study designs and statistical techniques cannot account for such dynamic complexities.

Given these problems, nomothetic studies have little potential to tell us something about causality at an individual level. Instead, they offer what may be called 'population causality'. Although the generalizability of the results of nomothetic studies to the population may be high, their applicability to specific individuals is low.

\section{The idiographic approach as an alternative}

If we are interested in effects applying to individuals, there is a more feasible alternative approach, referred to as the idiographic approach $[9,14,15]$. In this approach, power does not result from sample size but from the multitude of repeated measurements. The aim is to explain variance within individuals (intra-individual variation), and the unit of analysis is the individual, which is the most radical way of dealing with heterogeneity and confounding. The multitude of repeated assessments separated by short time lags allows evaluation of the temporal dynamics of the associations of interest, thereby greatly enhancing the possibility of drawing conclusions about causality. Several techniques for the analyses of such high-intensity time series data have been developed in fields such as econometrics and meteorology [16-18], but these techniques have to date hardly penetrated medical research. Capitalizing on the large number of measurements, it is possible to evaluate processes of change over time, bidirectional effects, feedback loops, non-linear effects, and complex dynamic interactions between multiple variables $[19,20]$, effects that are impossible to analyze properly using nomothetic designs. Idiographic studies have the potential to 
produce results that are of direct clinical relevance to individuals, enabling patient-tailored advice.

\section{Conclusion and perspectives}

The study by Stafford et al. is illustrative of some fundamental problems of the current research paradigm, which impede scientific progression. The nomothetic approach is essentially unfit to answer intra-individual questions, because what applies in aggregate is not necessarily informative for what is true for individuals [10]. However, a disadvantage of the idiographic approach, is that results from single individuals do not generalize well to the population at large. Therefore, a combination of nomothetic and idiographic methods, which takes into account both heterogeneity and dynamic complexity, but simultaneously tries to identify similarities and regularities across individuals and time, seems to be the way forward. Some promising steps in this direction have been made in recent years [21-24]. Such an approach should help to identify prototypical patients with specific etiological pathways, and thus arrive at knowledge that is not only useful for society but also valid in individuals.

\section{Competing interests}

Both authors declare no competing interests.

\section{Authors' contributions}

PDJ initiated the paper, and PDJ and EHB equally contributed to writing the paper. Both authors read and approved the final manuscript.

\section{Authors' information}

PDJ is a Professor of Psychiatric Epidemiology and Head of the Interdisciplinary Center Psychopathology and Emotion regulation, University Medical Center Groningen, University of Groningen, The Netherlands, who has been involved in several studies on the association between depression and cardiac disease. EB is a post-doctoral researcher at the same institution, who has a background in depression research and time-series analysis.

Received: 4 April 2013 Accepted: 4 April 2013

Published: 24 May 2013

\section{References}

1. Anda RF, Williamson DF, Escobedo LG, Mast EE, Giovino GA, Remington PL: Depression and the dynamics of smoking - a national perspective. JAMA 1990, 264:1541-1545.

2. Thorndike AN, Regan S, McKool K, Pasternak RC, Swartz S, Torres-Finnerty N, Rigotti NA: Depressive symptoms and smoking cessation after hospitalization for cardiovascular disease. Arch Int Med 2008, 168:186-191.

3. Khaled SM, Bulloch AG, Williams JV, Hill JC, Lavorato DH, Patten SB: Persistent heavy smoking as a risk factor for major depression (MD) incidence - evidence from a longitudinal Canadian cohort of the National Population Health Survey. J Psychiatr Res 2012, 46:436-443.

4. Nicholson A, Kuper H, Hemingway H: Depression as an aetiologic and prognostic factor in coronary heart disease: a meta-analysis of 6362 events among 146538 participants in 54 observational studies. Eur Heart J 2006, 27:2763-2774.

5. Berry JD, Dyer A, Cai X, Garside DB, Ning H, Thomas A, Greenland P, Van Horn L, Tracy RP, Lloyd-Jones DM: Lifetime risks of cardiovascular disease. N Engl J Med 2012, 366:321-329.

6. Stafford L, Berk M, Jackson HJ: Tobacco smoking predicts depression and poorer quality of life in heart disease. BMC Cardiovascular Disease 2013, 13:35.
7. Greenland S, Morgenstern H: Confounding in health research. Annu Rev Public Health 2001, 22:189-212.

8. Christenfeld NJS, Sloan RP, Carrol D, Greenland S: Risk factors, confounding, and the illusion of statistical control. Psychosom Med 2004, 66:868-875

9. Molenaar PCM: A Manifesto on psychology as idiographic science: bringing the person back into scientific psychology, this time forever. Measurement 2004, 24:201-218

10. Hamaker EL: Why researchers should think "within-person". In Handbook of Research Methods for Studying Daily Life. Edited by Mehl MR, Conner TS. New York, NY: The Guilford Press; 2012:43-61.

11. Wilson SE, Butler DM: A lot more to do: The sensitivity of time-series cross-section analyses to simple alternative specifications. Political Analysis 2007, 15:101-123.

12. Mohr C, Armeli S, Tennen H, Todd M: The complexities of modeling mood-drinking relationships: Lessons learned from daily process research. In Substance Abuse and Emotion. Edited by Kassel JD. Washington, DC: American Psychological Association; 2010:189-216.

13. Molenaar PCM, Campbell CG: The new person-specific paradigm in psychology. Cur Dir Psychol Sci 2009, 18:112-117.

14. Barlow DH, Nock MK: Why can't we be more idiographic in our research? Perspectives on Psychol Sci 2009, 4:19-21.

15. Allport GW: Personality: A Psychological Interpretation. New York: Holt, Rinehart, \& Winston; 1937.

16. Chatfield C: The Analysis of Time Series: An Introduction. 6th edition. London: Chapman \& Hall; 2004

17. Lütkepohl H: New Introduction to Multiple Time Series Analysis. Berlin: Springer Verlag; 2006.

18. Brandt PT, Williams JT: Multiple Time Series Models. Thousand Oaks, CA: Sage Publications; 2007.

19. Van Geert P: The contribution of complex dynamic systems to development. Child Developmental Perspectives 2011, 5:273-278

20. Hoenders HJR, Bos EH, de Jong JTVM, de Jonge P: Temporal dynamics of symptom and treatment variables in a lifestyle-oriented approach to anxiety disorder. A single-subject time-series analysis. Psychother Psychosom 2012, 81:253-255.

21. Jenson WR, Clark E, Kircher JC, Kristjansson SD: Statistical reform: evidencebased practice, meta-analysis, and single-subject designs. Psychol Schs 2007, 44:483-493.

22. Horváth C, Wieringa JE: Pooling data for the analysis of dynamic marketing systems. Statistica Neerlandica 2008, 62:208-229.

23. Houtveen JH, Hamaker EL, van Doornen LP: Using multilevel path analysis in analyzing 24-h ambulatory physiological recordings applied to medically unexplained symptoms. Psychophysiology 2012, 47:570-578.

24. Gates KM, Molenaar PC: Group search algorithm recovers effective connectivity maps for individuals in homogeneous and heterogeneous samples. Neuroimage 2012, 15:310-319.

doi:10.1186/1741-7015-11-138

Cite this article as: de Jonge and Bos: Tobacco smoking and depression: time to move on to a new research paradigm in medicine? BMC Medicine 2013 11:138.

\section{Submit your next manuscript to BioMed Central and take full advantage of:}

- Convenient online submission

- Thorough peer review

- No space constraints or color figure charges

- Immediate publication on acceptance

- Inclusion in PubMed, CAS, Scopus and Google Scholar

- Research which is freely available for redistribution 